09

\title{
Электроразрядный химический HF-лазер - высококогерентный источник для ИК-голографии. Перспективы практического применения
}

\author{
(C) О.Г. Федотов, В.М. Фомин
}

Научно-исследовательский институт электрофизической аппаратуры, 196641 Санкт-Петербург, Россия

e-mail: vitfominm@gmail.com

(Поступило в Редакцию 3 апреля 2017 г. В окончательной редакции 23 июля 2017 г.)

\begin{abstract}
Приведены предварительные результаты экспериментов по записи фазовых и амплитудных голограмм под действием излучения электроразрядных НF-лазеров и обсуждаются перспективы использования таких лазеров для диагностики различных объектов. Показано, что при обеспечении достаточно высокой степени однородности активной среды лазера излучение характеризуется высокой степенью когерентности (длина когерентности может превышать $6 \mathrm{~m}$ ) без применения каких-либо специальных мер по селекции модового состава. Рассматрены возможности контроля пространственного распределения концентрации электронов в эксимерных и электроразрядных химических $\mathrm{HF}(\mathrm{DF})$-лазерах, а также контроля распределения основных выгорающих компонент таких лазеров. Продемонстрирована потенциальная возможность нанесения голографических идентификационных меток на произведения живописи.
\end{abstract}

DOI: 10.21883/JTF.2018.02.45418.2275

\section{Введение}

Известно [1,2], что использование лазеров инфракрасного диапазона спектра при голографической диагностике плазмы имеет определенные преимущества по отношению к лазерам видимого диапазона. Это связано с тем, что чувствительность определения концентрации электронов прямо пропорциональна длине волны зондирующего излучения при том, что чувствительность интерференционной картины к градиенту плотности нейтральных частиц обратно пропорциональна длине волны. То есть при интерференционной диагностике плазменных объектов в среднем инфракрасном диапазоне погрешность измерения распределения электронной концентрации, связанная с градиентом плотности тяжелых частиц, в большинстве случаев пренебрежимо мала. В соответствии с этим минимально определяемое значение произведения концентрации электронов $\left(N_{e}\right)$ на длину плазменного объекта $(L)$ можно рассчитать по известной формуле [2]:

$$
\left(N_{e} L\right)_{\min } \approx 2.2 \cdot 10^{13} k_{\min } /\left(C_{S} \lambda\right) \mathrm{cm}^{-2},
$$

где $\lambda$ - длина волны зондирующего излучения, $k_{\min }-$ минимально определяемый сдвиг интерференционной полосы (обычно принимается значение 0.1 полосы), $C_{S}$ - коэффициент чувствительности.

Коэффициент чувствительности прямо пропорционально зависит от количества проходов зондирующего излучения по диагностируемому объекту и степени нелинейности голограммы. При восстановлении голограмм в $\pm n$ порядках дифракции чувствительность определения концентрации электронов возрастает в $2 n$ раз [2].
В прошлом столетии в нашей стране и за рубежом была продемонстрирована возможность и эффективность диагностики распределения концентрации электронов в различных плазменных объектах с помощью $\mathrm{CO}_{2}$-лазеров [1,2] (см. также ссылки в этих работах). При диагностике таких объектов, как дуговой разряд, реализована запись и восстановление нелинейных голограмм вплоть до 7-го порядка дифракции и схема компенсации аберраций, возрастающих вместе с порядком дифракции.

В настоящее время $\mathrm{CO}_{2}$-лазеры с успехом применяются как для диагностики плазмы $[3,4]$, так и для интерферометрического контроля формы и деформации разнообразных объектов, таких как крупногабаритные зеркала [5], строительные сооружения [6], произведения искусства [7]. В последнем случае интерферограмма, фиксирующая скрытые дефекты произведения живописи, сохраненная на электронном носителе, выполняет функцию индивидуальной „идентификационной метки“, снижающей вероятность подмены подлинника картины копией.

В 70-х годах прошлого века в работах $[8,9]$ использовались электроразрядные нецепные фтороводородные химические лазеры для диагностики плазмы. В этих работах были получены распределения концентрации электронов в плазме разряда в конфигурации $Z$ - и $\theta$-пинча. Запись голограмм осуществлялась на пленках из желатины и висмута. При облученности желатины на уровне $2 \mathrm{~J} / \mathrm{cm}^{2}$ записывалась интерференционная картина с пространственной частотой $300 \mathrm{~mm}^{-1}$ [8]. На висмутовой пленке при облученности $0.5-1.0 \mathrm{~J} / \mathrm{cm}^{2}$ разрешающая способность была не хуже $500 \mathrm{~mm}^{-1}$, пороговая плотность записи не превышала $0.1 \mathrm{~J} / \mathrm{cm}^{2}[9]$. 
При изучении разряда $\theta$-пинча, формируемого в цилиндрической кварцевой колбе [8], используемый лазер генерировал в неселективном режиме. Записывалась суперпозиция из 5-8 фазовых голограмм, последовательное восстановление которых позволило снизить погрешность определения концентрации электронов. Измеренное минимальное значение $\left(N_{e} L\right)$ составило $10^{16} \mathrm{~cm}^{-2}$. В работе [9] лазер генерировал на одной линии, записывались амплитудные голограммы, минимальное значение $\left(N_{e} L\right)$ составило $8 \cdot 10^{15} \mathrm{~cm}^{-2}$.

В работе [10] была также продемонстрирована возможность голографического метода для получения данных о пространственном распределении спектрального состава излучения фтороводородных лазеров и зависимости спектра генерации от исходного давления лазерной смеси.

Очевидным образом, уступая в чувствительности определения концентрации электронов, НF-лазеры обладают определенными преимуществами по отношению к $\mathrm{CO}_{2}$-лазерам. Излучение HF-лазеров с небольшими потерями проникает через стенки кварцевых колб, в которых формируются различные плазменные образования, например, через стенки ксеноновых и эксиплексных ламп и практически без потерь проходит через выводные или диагностические окна, прозрачные в видимом и ультрафиолетовом диапазонах спектра.

Однако методика голографической диагностики плазмы с использованием НF-лазеров развития в дальнейшем не получила. Это было связано с отсутствием удобных регистрирующих материалов, имеющих низкий порог записи, что требовало применения лазеров с высоким значением выходной энергии. Такие лазеры в то время были довольно сложными, громоздкими установками. Так, в [8] для записи голограмм на желатиновой пленке использовался лазер с многоострийным (2000 шт.) катодом. Длина разрядной камеры составляла $3 \mathrm{~m}$, энергия генерации - 10J. В [9] для записи голограмм на висмутовой пленке использовалась система генераторусилитель, с селекцией поперечных мод с выходной энергией $2.5 \mathrm{~J}$ (КПД $\sim 0.2 \%$ ).

В настоящей работе приводятся предварительные результаты изучения возможности записи голограмм излучением электроразрядых НF-лазеров с умеренным значением выходной энергии - 0.07-1.5 J. Обсуждаются возможности использования $\mathrm{HF}(\mathrm{DF})$-лазеров для диагностики плазмы, в частности, для изучения плазмохимической кинетики эксимерных и химических лазеров.

\section{Экспериментальная установка}

Эксперименты проводились с использованием двух лазерных установок, разработанных в НИИЭФА им. Д.В. Ефремова.

В первой из них формирование объемного разряда в смеси гексафторида серы и водорода осуществлялось за
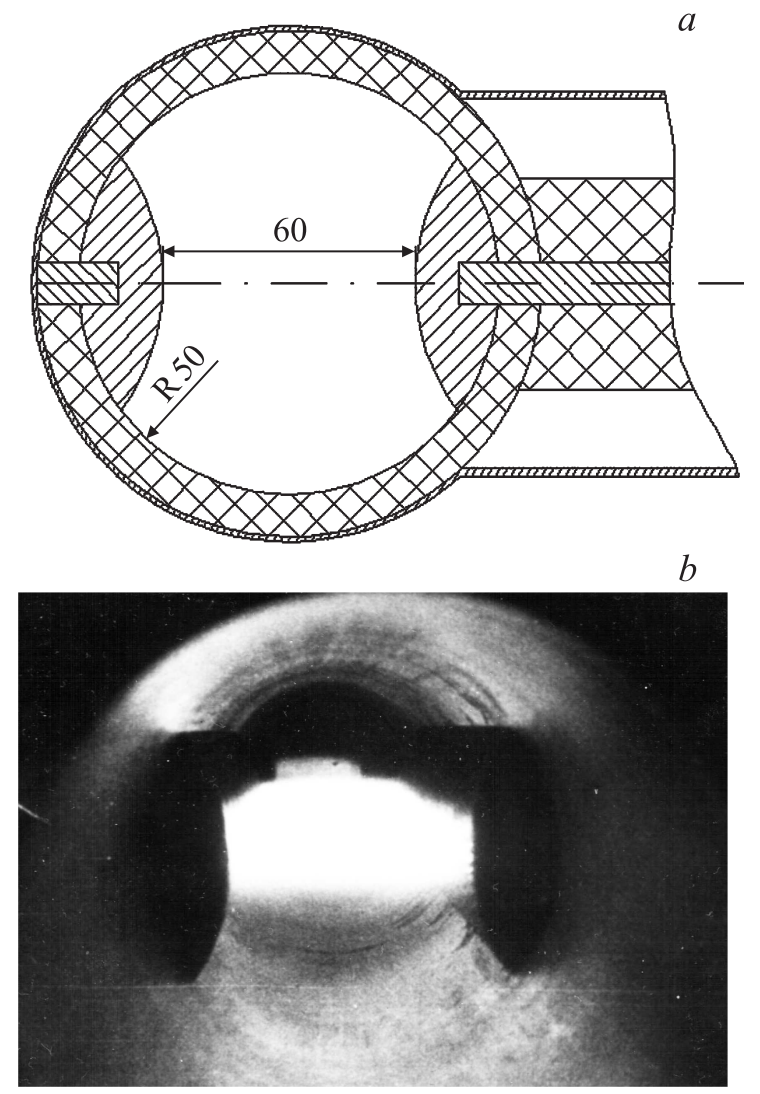

Рис. 1. Эскиз разрядной камеры $(a)$ и фотография разрядного промежутка $(b)$.

счет рентгеновской предыонизации излучением скользящего разряда [11]. Скользящий разряд формировался по стенкам разрядной камеры - фторопластовой трубы с внутренним диаметром $100 \mathrm{~mm}$ при приложении к межэлектродному промежутку импульса напряжения амплитудой до $400 \mathrm{kV}$ длительностью $50 \mathrm{~ns}$ с фронтом $<10$ ns. Особенностью используемой системы формирования объемного разряда является параллельное формирование скользящего и объемного разрядов в одном межэлектродном промежутке. Скользящий разряд формировался при высокой скорости нарастания напряжения на межэлектродном промежутке, достаточной для генерации убегающих электронов и эмиссии потока мягкого рентгеновского излучения [12]. Снижение напряжения на разрядном промежутке, связанное с формированием объемного разряда, уменьшало частоту ионизации в слое скользящего разряда и при достаточно малом значении длительности прикладываемого напряжения препятствовало переходу плазмы скользящего разряда в высокопроводящее состояние.

На торцах разрядной камеры были установлены окна из фторида кальция (флюорита), ориентированные нормально к оптической оси. В исходном варианте [11] электроды лазера устанавливались на расстоянии $6 \mathrm{~cm}$ друг от друга, имели ширину плоской части $-6 \mathrm{~cm}$, 


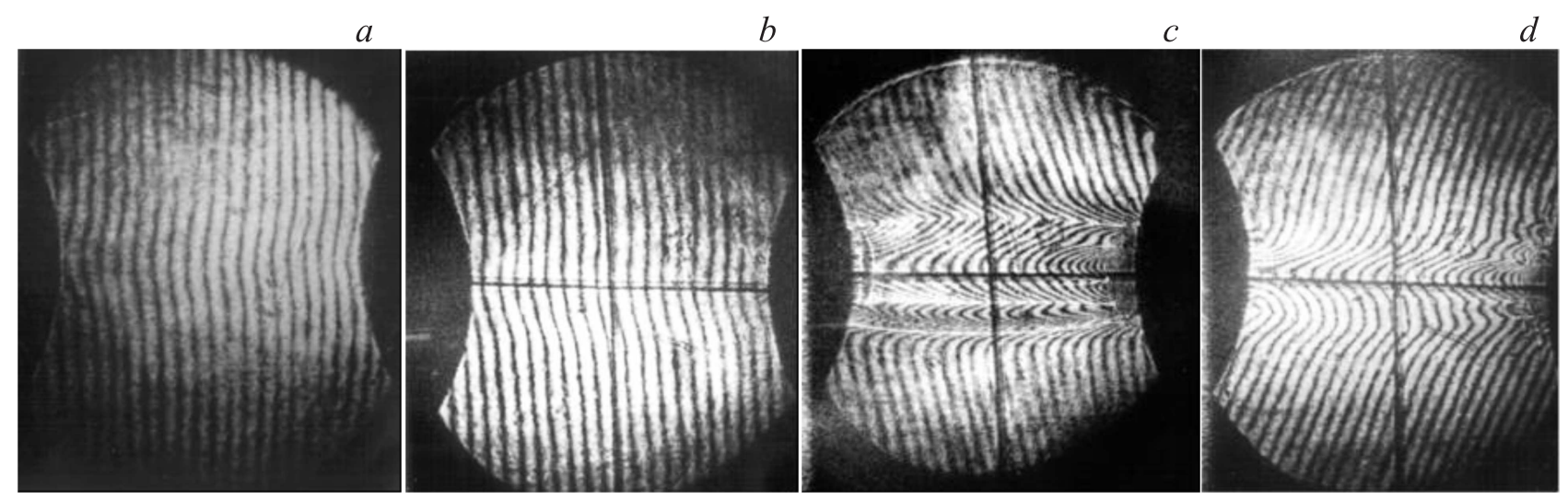

Рис. 2. Интерферограммы объемного разряда в $\mathrm{SF}_{6}$, зарегистрированные с задержкой: $a-0.28, b-0.7, c-20, d-15 \mu \mathrm{s}$; давление элегаза: $a, b, c-10 \mathrm{kPa}, d-5 \mathrm{kPa}$; приложенное напряжение: $a, b, c-250 \mathrm{kV}, d-210 \mathrm{kV}$.

длину - $50 \mathrm{~cm}$. Лазерный пучок имел в поперечнике размеры $6 \times 6 \mathrm{~cm}$. Однако распределение плотности энергии генерации такого лазера было немонотонным, на оси симметрии наблюдался минимум излучения.

При проведении настоящей работы в разрядную камеру лазерной установки были установлены сегментноцилиндрические электроды с радиусом кривизны $5 \mathrm{~cm}$. Величина приложенного напряжения была снижена до $250 \mathrm{kV}$. Эскиз разрядной камеры приведен на рис. 1, там же приведена фотография плазмы объемного разряда при давлении элегаза $10 \mathrm{kPa}$.

Резонатор длиной $1 \mathrm{~m}$ состоял из плоских зеркал. Глухое зеркало имело алюминиевое покрытие, выходное зеркало имело коэффициент отражения в спектральной полосе генерации лазера (2.6-3.0) $\mu \mathrm{m} \sim 50 \%$.

Перед выполнением настоящей работы была проведена серия экспериментов по изучению условий формирования однородного объемного разряда в лазере с рентгеновской предыонизацией. С помощью голографической установки на базе рубинового лазера ОГМ-20 [13] контролировалось распределение оптической плотности объемного разряда. На рис. 2 представлены характерные интерферограммы объемного и скользящего разрядов. Ввиду того, что апертура зондирующего пучка $(\sim 90 \mathrm{~mm})$ была меньше внутреннего диаметра разрядной камеры, для визуализации скользящего разряда оптическая ось голографической установки поднималась на $10 \mathrm{~mm}$ (рис. 2, $c, d$ ).

В выбранном режиме работы при давлении 5-15 $\mathrm{kPa}$ газовой смеси $\mathrm{SF}_{6}: \mathrm{H}_{2}=12: 1$ активная среда лазера была весьма однородна. Существенные возмущения газовой смеси наблюдались только после завершения импульса генерации. Область, занимаемая объемным разрядом, составляла $1.6 \times 6 \times 50 \mathrm{~cm}$, энергия генерации $-1.5 \mathrm{~J}$, длительность импульса генерации - $150 \mathrm{~ns}$. О высоком оптическом качестве активной среды лазера свидетельствовало также формирование лазерной искры в воздухе, наблюдаемой при фокусировке излучения сферическим зеркалом с фокусным расстоянием $160 \mathrm{~mm}$.
В процессе выполнения работы использовался также электроразрядный лазер ФЛИП-1 [14] — первый отечественный импульсно-периодический химический лазер с замкнутым газодинамическим контуром.

Перед проведением экспериментов в конструкцию электродного узла и системы инициирования лазера [14] были введены изменения, позволившие увеличить ширину области, занимаемой электроразрядной плазмой, и равномерность распределения энерговклада в объемный разряд. При этом КПД лазера вырос до 3\%, при зарядном напряжении $25 \mathrm{kV}$ энергия генерации в импульсе составляла $85 \mathrm{~mJ}$. Формирование объемного разряда длительностью $\sim 100 \mathrm{~ns}$ осуществлялось с УФ-предыонизацией излучением многоискрового разряда в цепи обостряющей емкости. Длина плоской части электродов составляла $30 \mathrm{~cm}$, межэлектродное расстояние $14 \mathrm{~mm}$, ширина разрядной зоны была близка к величине
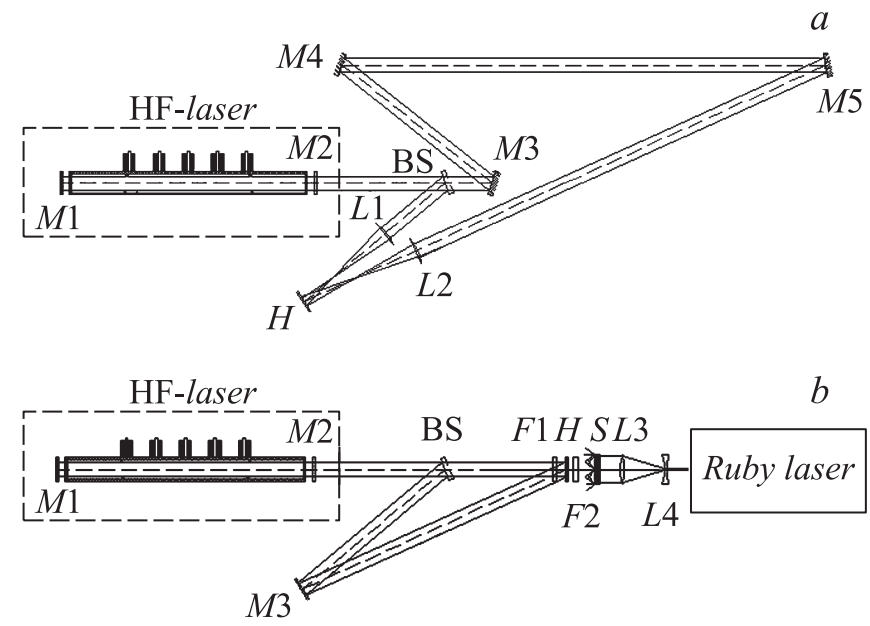

Рис. 3. Оптическая схема эксперимента: $a-$ запись фазовых голограмм, $b-$ запись амплитудных голограмм; $M 1-M 5-$ плоские зеркала, $L 1-L 4-$ линзы, $F 1$ и $F 2$ - оптические фильтры, $B S-$ светоделительная германиевая пластина, $S-$ диффузор, $H-$ регистратор. 
межэлектродного промежутка $(16 \mathrm{~mm})$. Длительность импульса генерации при соотношении компонентов газовой смеси $\mathrm{SF}_{6}: \mathrm{H}_{2}=6: 1$ составляла $\sim 100 \mathrm{~ns}$.

В лазерах обоих типов длительность импульса генерации могла быть легко уменьшена до $50 \mathrm{~ns}$ за счет увеличения содержания водорода в газовой смеси.

Упрощенная оптическая схема записи голограмм приведена на рис. 3. Разделение выходного пучка на „опорный“ и „референтный“ осуществлялось с помощью германиевой пластины BS. Разность хода лучей могла изменяться от 1 до $6.5 \mathrm{~m}$. В ходе работы осуществлялась запись фазовых и амплитудных голограмм.

При записи фазовых голограмм пучки „фокусировались“ флюоритовыми линзами $L 1, L 2$ на желатиновой пленке $H$, покрывающей засвеченную фотопленку (фотопластинку), или пленку отбеленного льняного масла, нанесенную на флюоритовую пластину (льняное масло широко используется в живописи для нанесения защитной пленки).

При записи амплитудных голограмм пучки направлялись на фотопленку ФПГВ-2, сенсибилизированную на длину волны рубинового лазера. При этом запись осуществлялась по известному методу тепловой сенсибилизации (см., например, [15]), когда инфракрасное излучение создает тепловой рельеф на поверхности фотопленки, скрытое изображение которого формируется за счет фотохимического воздействия на фотопленку излучения видимого диапазона спектра (излучаемого, например, ксеноновой лампой-вспышкой).

В нашей работе в качестве источника актиничного облучения мы применяли рубиновый лазер ОГМ-20, использовавшийся для голографической диагностики однородности объемного разряда. Излучение рубинового лазера, прошедшее через диффузный рассеиватель $S$, облучало фотопленку с тыльной стороны. Лазер подсветки работал в режиме модулированной добротности, длительность импульса генерации составляла $\sim 100 \mathrm{~ns}$, время задержки между импульсами генерации химического и рубинового лазеров варьировалось в пределах $0.1-10 \mu \mathrm{s}$. Для предотвращения некогерентной засветки фотопленка защищалась фильтрами $F 1$ и $F 2$ из германия и стекла КС-18 соответственно.

\section{Результаты эксперимента и их обсуждение}

На рис. 4 приведен фрагмент увеличенного изображения фазовой голограммы. Фазовые голограммы были записаны за счет изменения рельефа поверхности желатиновой пленки под воздействием мощного лазерного излучения. Нелинейные голограммы восстанавливались с высоким качеством в \pm 6 -х порядках дифракции, что, как известно $[1,2]$, позволяет повысить чувствительность определения $\left(N_{e} L\right)$ в 12 раз. При плотности энергии облучения $\sim 0.5 \mathrm{~J} / \mathrm{cm}^{2}$ пространственная частота записанных решеток изменялась в диапазоне $100-140 \mathrm{~mm}^{-1}$,

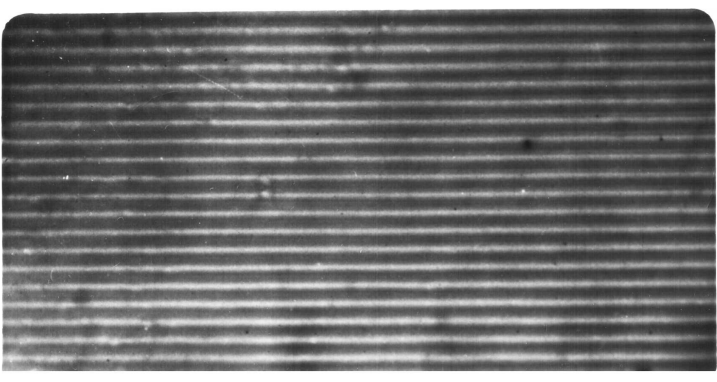

Рис. 4. Фрагмент увеличенного изображения фазовой голограммы на желатиновой пленке.

что соответствовало значениям разности углов падения лазерных пучков на записывающую среду. Динамический диапазон при этом был не менее 3 , дифракционная эффективность в \pm 1 -х порядках составляла $\sim 10 \%$ и имела достаточно однородное распределение по полю изображения. При изменении разности хода лучей до $6.5 \mathrm{~m}$ дифракционная эффективность практически не изменялась. Для сравнения заметим: длина когерентности эрбиевого лазера $[15](\lambda=2.94 \mu \mathrm{m})$ составляла всего $3.3 \mathrm{~cm}$.

Дифракционная эффективность амплитудных голограмм при плотности экспозиции $0.1 \mathrm{~J} / \mathrm{cm}^{2}$ была значительно меньше и составляла $\sim 1 \%$. Пространственная частота записанной решетки составляла $\sim 120 \mathrm{~mm}^{-1}$. При изменении задержки между импульсами излучения химического лазера и лазера подсветки до $10 \mu \mathrm{s}$ существенного снижения дифракционной эффективности отмечено не было.

При воздействии потока излучения лазера ФЛИП-1 (с энергией в импульсе $60 \mathrm{~mJ}$ ), разделенного на два пучка примерно равной интенсивности с разностью хода, не превышающей $1 \mathrm{~m}$, дифракционная решетка записывалась на различных материалах, таких как желатина, металлизированный лавсан, пленка из высохшего льняного масла. При воздействии излучения на пленку из льняного масла, нанесенную на флюоритовую пластину, при плотности экспозиции $\sim 1 \mathrm{~J} / \mathrm{cm}^{2}$ на ней записывалась дифракционная решетка. Фрагмент увеличенного изображения поверхности лаковой пленки приведен на рис. 5. При облучении экспонированного образца излучением $\mathrm{He}-\mathrm{Ne}$-лазера наблюдалось расщепление проходящего и отраженного пучков на 7 лучей (в течение 10 лет после записи). В солнечном свете голограмма наблюдалась также в проходящих и отраженных лучах под определенными углами в виде радужного пятна.

Этот результат открывает интересные перспективы исследований, направленных на использование фторводородных лазеров для нанесения уникальных идентификационных меток (art security encoding) на произведениях живописи. 


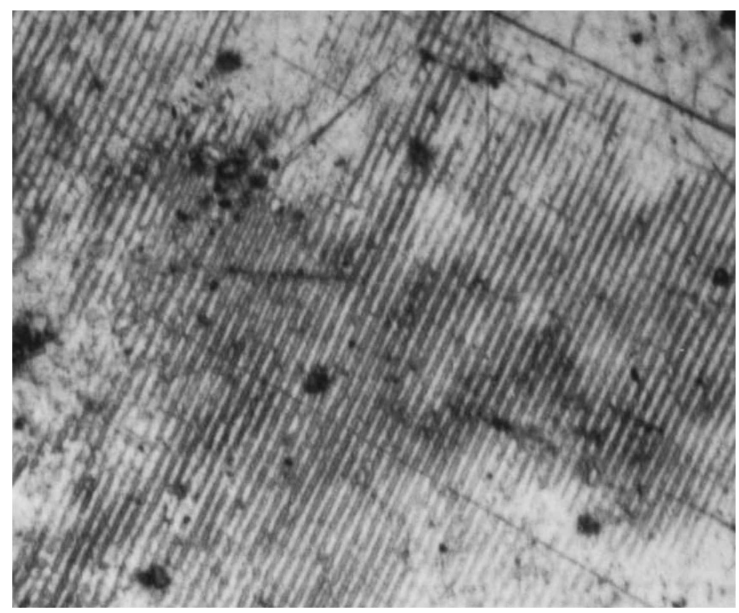

Рис. 5. Фрагмент увеличенного изображения дифракционной решетки на поверхности пленки из льняного лака.

После облучения желатинового слоя засвеченной фотопленки и металлизированного лавсана при отражении луча Не-Ne-лазера наблюдалось расщепление на 5 и 3 луча соответственно. При этом необходимо отметить, что в лазере ФЛИП-1 объемный разряд был менее однороден, чем разряд в лазере с рентгеновской предыонизацией. В структуре разряда наблюдались отдельные струи диаметром 4-5 mm.

Полученные результаты демонстрируют то обстоятельство, что при обеспечении достаточно однородного по объему инициирования электроразрядных химических лазеров излучение характеризуется высокой степенью когерентности без применения каких-либо специальных мер по селекции модового состава.

Чувствительность определения концентрации электронов при диагностике плазмы с помощью НF-лазеров может быть повышена в 40 раз по отношению к рубиновому лазеру.

В настоящей работе получены данные, характеризующие когерентные характеристики нецепных химических лазеров, генерирующих на молекуле фтористого водорода. У нас нет сомнений, что практически значимых изменений в степени когерентности излучения при переходе на генерацию на молекулах фтористого дейтерия $(\lambda=3.4-4 \mu \mathrm{m})$ не произойдет.

C учетом данных о спектре поглощения желатины (стандартной [16] и дейтерированной [17]), экспериментальных результатов [15] можно ожидать, что пороговая плотность энергии записи голограмм методом тепловой сенсибилизации не превысит значения $-1 \mathrm{~mJ} / \mathrm{cm}^{2}$ при облучении как HF-, так и DF-лазером.

Практическая реализация того или иного метода записи голограмм под действием излучения DF-лазера не только позволит повысить чувствительность определения концентрации электронов, но и расширить круг решаемых задач.

\section{Перспективы использования}

При рассмотрении перспектив использования HF- и DF-лазеров в качестве источников излучения интерферометрических диагностических установок необходимо отметить, что лазерный источник, который в основном использовался при проведении описанных экспериментов, был уникальным и отчасти обладал теми же недостатками, что и предшествующие ему установки сложностью конструкции и эксплуатации.

Развитие техники инициирования электроразрядных нецепных химических лазеров [18-21], успехи в разработке тиратронов с холодным катодом [22] делают создание „коммерческого“ $\mathrm{HF}(\mathrm{DF})$-лазера с небольшой частотой повторения, естественно, с замкнутым газодинамическим контуром, включающим систему очистки [14], с выходной энергией 1-2 J вполне разрешимой инженерной задачей.

На наш взгляд, оптимальным вариантом реализации голографической установки является использование лазера с резистивной стабилизацией объемного разряда с помощью монолитных электродов, изготовленных из титаносодержащей керамики, легированной ниобием. Такая электродная система стабилизации объемного разряда в газовой смеси НF-лазера, предложенная в работе [23], продемонстрировала свою надежность и эффективность при инициировании импульсно-периодических цепных и нецепных $\mathrm{HF}(\mathrm{DF})$-лазеров [21].

Другим важным фактором, обеспечивающим в настоящее время возможность эффективного использования HF- и DF-лазеров для голографической интерферометрии различных объектов, является наличие удобных в эксплуатации неохлаждаемых матричных фотоприемников, обладающих высокой чувствительностью в спектральном диапазоне генерации таких лазеров. Так, например, камера PIROCAM IV (Ophir Optronics) позволяет записывать интерферограммы размерами $2.54 \times 2.54 \mathrm{~cm}$ с разрешением $80 \mu \mathrm{m}$, с чувствительностью $10 \mathrm{~mJ} / \mathrm{cm}^{2}$ и динамическим диапазоном 1000 .

При записи голограмм методом тепловой сенсибилизации в качестве источника актиничного излучения можно использовать вполне доступные в настоящее время „быстрые“ импульсные светодиоды.

На наш взгляд, высококогерентные $\mathrm{HF}(\mathrm{DF})$-лазеры могут найти применение при решении ряда актуальных задач.

Из многочисленных плазменных объектов, при диагностике которых могут быть использованы HF- и DF-лазеры, выделим электроразрядные лазеры: длинноимпульсные эксимерные и электроразрядные химические.

В эксимерных ХеCl-лазерах концентрация электронов может достигать значений $10^{15}-10^{16} \mathrm{~cm}^{-3}$ [24-26]. При достаточной протяженности разрядного промежутка значение $\left(N_{e} L\right)$ в большинстве случаев достаточно велико для голографической диагностики поперечного распределения концентрации электронов в меж- 
электродном промежутке при использовании в качестве источника излучения рубинового лазера. Так, в работе [26] при измерении концентрации электронов с помощью рубиновых лазеров в разрядном промежутке длиной $80 \mathrm{~cm}$ наблюдалось смещение интерференционных полос $\sim 0.75$ в максимуме тока (при концентрации электронов $3 \cdot 10^{15} \mathrm{~cm}^{-3}$ ), а также прорастание каналов от катода к аноду. При использовании в качестве источника зондирующего излучения HF-лазера и восстановлении голограмм в первом порядке дифракции при диагностике XeCl-лазера [26] смещение составит более 3 полос, точность диагностики распределения электронной концентрации возрастет в 4 раза.

При записи нелинейных голограмм может быть также визуализировано распределение концентрации электронов не только поперек, но и вдоль электродов, в областях их торцов - критических с точки зрения обеспечения устойчивости разряда и формирования диаграммы направленности излучения. Так, при восстановлении нелинейной голограммы в 4-м порядке, записанной при диагностике лазера, описанного в [26], смещение в максимуме тока составит $\sim 1$ полосу.

Не вызывает сомнения возможность голографической диагностики $\mathrm{KrF}$ и других эксимерных лазеров, функционирующих в длинноимпульсном режиме, с длительностью импульса тока, превосходящей $100 \mathrm{~ns}$.

В электроразрядных химических лазерах концентрация электронов в максимуме тока в соответствии с расчетными данными $[27,28]$ может достигать значения $2 \cdot 10^{14} \mathrm{~cm}^{-3}$, приведенная поверхностная плотность электронов $\left(N_{e} L\right)-10^{16} \mathrm{~cm}^{-2}[28,29]$. При двукратном прохождении излучения DF-лазера $(\lambda \approx 3.8 \mu \mathrm{m})$ через активную среду НF-лазера [29] может быть записана линейная голограмма, смещение в максимуме тока составит $\sim 0.33$ полосы.

Известно [2], что линейная голограмма фиксирует не только фазовые, но и амплитудные искажения предметной волны. Преимуществом голографического метода измерения поглощения является его нечувствительность к собственному излучению плазмы (активной среды лазеров), которое, будучи некогерентным, не участвует в формировании интерференционной структуры голограммы. Возможность весьма точного измерения коэффициента поглощения голографическим методом была продемонстрирована в работе [30]. С учетом этого обстоятельства представляется весьма перспективным использование DF-лазеров для контроля изменения концентрации выгорающих компонент газовых смесей электроразрядных лазеров, таких как хлористый водород в эксимерных $\mathrm{XeCl}(\mathrm{KrCl}, \mathrm{ArCl})$-лазерах и предельные углеводороды $\mathrm{C}_{2} \mathrm{H}_{6}, \mathrm{C}_{3} \mathrm{H}_{8}, \mathrm{C}_{4} \mathrm{H}_{10}-$ в химических фтороводородных.

Как известно, излучение линии генерации 2P(3) DFлазера сильно поглощается молекулами $\mathrm{HCl}$ [31]. По данным [25] степень выгорания этого компонента лазерной смеси к моменту прекращения тока через раз- рядный промежуток может достигать 90\%. Приведенный коэффициент поглощения хлористого водорода, находящегося в азоте (при атмосферном давлении), весьма высок - более $5 \mathrm{~m}^{-1} \mathrm{kPa}^{-1}$ [31]. Начальное парциальное давление хлористого водорода в смесях ХеCl-лазеров находится в пределах $0.1-1 \mathrm{kPa}$, при типичной длине электродов $\sim 70 \mathrm{~cm}$ коэффициент поглощения за проход составит $\sim 0.3-0.97$. Точность измерения больших концентраций $\mathrm{HCl}$ может быть повышена за счет использования другой линии генерации $P_{2}(4)$, имеющей меньшее значение коэффициентов поглощения $0.015 \mathrm{~m}^{-1} \mathrm{kPa}^{-1}$ [31]. Высокая степень поглощения линии $2 P(3)$ может позволить контролировать пространственную структуру выгорания $\mathrm{HCl}$ не только поперек, но и вдоль оптической оси лазерной установки.

Коэффициенты поглощения молекулами $\mathrm{C}_{2} \mathrm{H}_{6}, \mathrm{C}_{3} \mathrm{H}_{8}$, $\mathrm{C}_{4} \mathrm{H}_{10}$, которые используются в качестве доноров водорода нецепных электроразрядных НF-лазеров на линиях генерации DF-лазеров, составляют $0.1-0.2 \mathrm{~m}^{-1} \mathrm{kPa}^{-1}$ [32]. Характерное давление углеводорода $\sim 0.5 \mathrm{kPa}$, характерная степень выгорания доноров водорода по нашим оценкам составляет $\sim 50 \%$. Поэтому задача определения пространственного поля выгорания этих веществ более сложна в метрологическом и феноменологическом плане, но, на наш взгляд, вполне реализуема. Голографический метод позволит не только исключить влияние засветки сверхизлучением активной среды лазера, но и использовать возможности, связанные с вариацией пороговой плотности записи голограмм, так чтобы облученность в области максимума интерференционной полосы в невозмущенной среде была ниже заданного порогового значения. Чувствительность метода и точность определения концентрации донора водорода могут быть повышены также за счет введения в опорный пучок кюветы с газовой смесью, в которой содержание углеводородов варьировало бы в необходимых пределах.

Помимо импульсных электроразрядных эксимерных и химических лазеров естественным объектом для изучения пространственных характеристик являются импульсно-периодические и непрерывные цепные химические $\mathrm{HF}(\mathrm{DF})$ - лазеры, в которых может быть визуализировано распределение молекул НF или DF в активной среде таких лазеров.

По-прежнему актуальной представляется задача определения распределения концентрации электронов в плазме ксеноновых ламп, используемых для накачки лазеров и решения других задач.

Весьма актуальным направлением использования HF-лазера может стать нанесение голографических идентификационных меток на поверхности картин, которые исключат возможность их подмены. В настоящее время за рубежом для этих целей, в частности, используются эксимерные лазеры, с помощью которых на поверхностях картин записываются компьютерно-генерируемые голограммы [33]. 


\section{Заключение}

Представленные в работе результаты носят предварительный характер и требуют уточнения. В первую очередь необходимо определить пороговые значения экспозиции и чувствительность записи голограмм на различных материалах под действием излучения отдельных линий генерации HF- и DF-лазеров.

Следует отметить, что процессы записи и восстановления голограмм (в особенности нелинейных) являются сложной экспериментальной задачей, но решение задач определения пространственного распределения концентрации электронов и выгорающих компонент эксимерных и химических лазеров позволит существенным образом повысить достоверность и предсказательную силу математических моделей расчета характеристик таких лазеров.

Представленная работа проведена по инициативе и под руководством В.Г. Смирнова и посвящена его памяти.

\section{Список литературы}

[1] Зайдель А.Н., Островская Г.В., Островский Ю.И. // ЖТФ. 1968. Т. 38. Вып. 9. С. $1405-1409$.

[2] Островская Г.В. // ЖТФ. 2008. Т. 78. Вып. 9. С. 1-28.

[3] Acedo P., Lamela H., Sanchez M., Estrada T., Sanchez J. // Rev. Sci. Instrum. 2004. Vol. 75. N 11. P. 4671-4677.

[4] Thomas C.E., Baylor Jr.L.R, Combs S.K., Meitner S.J., Rasmussen D.A., Granstedt E.M., Majeski R.P., Kaita R. // Rev. Sci. Instrum. 2010. Vol. 81. N 10. P. 527-1-527-7.

[5] Georges M.P., Vandenrijt J.F., Thizy C., Stockman Y., Queeckers P., Dubois F., Doyle D. // Appl. Opt. 2013. Vol. 52. N 1. P. $102-116$.

[6] Alexeenko I., Vandenrij J.F., Georges M., Pedrini G., Cédric T., Osten W., Vollheim B. // Appl. Mech. Mater. 2010. Vol. 24-25. P. 147-152.

[7] Tornari V., Bernikola E., Osten W., Groves R.M., Marc G., Hustinx G.M., Hackney S. // Proc. SPIE. 2007. Vol. 6618. P. 715-716.

[8] Braun W. // Phys. Lett. A. 1974. Vol. 47. N 2. P. 144-146.

[9] Kristal R. // Appl. Opt. 1975. Vol. 14. N 3. P. 628-633.

[10] Braun W.W. // Opt. Eng. 1975. Vol. 14. N 3. P. 208-209.

[11] Бурцев В.А., Водовозов В.М., Дашук П.Н., Кулаков С.Л., Прокопенко В.Ф., Фомин В.М., Челноков Л.Л. // Тез. докл. II Всесоюзн. совещания по физике электрического пробоя газов. Тарту, 1984. С. 414-418.

[12] Дашук П.Н., Кулаков С.Л. // Письма в ЖТФ. 1981. Т. 7. Вып. 14. С. 853-857.

[13] Буриев В.А., Зеленов Л.А., Камардин И.Л., Курунов Р.Ф., Кучинский А.А., Раткевич В.К., Родичкин В.А., Смирнов В.Г., Шанский В.Ф. // Квант. электрон. 1988. Т. 15. № 1. C. 167-172.

[14] Бурцев В.А., Безгрешнов М.В., Финкельштейн К.И., Фомин В.M. // Тез. докл. Всесоюзн. конф. Физика и конверсия. Калининград, 1991. С. 161.

[15] Вадковская Т.Н., Дрожбин Ю.А., Лобачев В.А., Мурина Т.М., Прохоров А.М., Трофименко В.В. // Квант. электрон. 1988. Т. 15. № 1. С. 229-232.
[16] Картужсанский Л.А., Мишунин И.Ф., Центровский В.А. // Укр. физ. журн. 1978. Т. 23. № 2. С. 267-273.

[17] Горлин Т.Б., Парицкий Л.Г., Тиснек Т.В. // ЖТФ. 1987. Т. 57. Вып. 1. С. 159-163.

[18] Аполлонов В.В., Казанцев С.Ю., Орешкин В.Ф., Фирсов К.Н. // Квант. электрон. 1998. Т. 25. № 2. С. 123-125.

[19] Булаев В.Д., Гусев В.С., Казанцев С.Ю., Кононов И.Г., Льсенко С.Л., Морозов Ю.Б., Познышев А.Н., Фирсов К.Н. // Квант. электрон. 2010. Т. 40. № 7. С. 615-618.

[20] Панченко А.Н., Тарасенко В.Ф. // Письма в ЖТФ. 2004. Т. 30. Вып. 11. С. 22-28.

[21] Климук Е.А., Кутумов К.А., Трощиненко Г.А. // Квант. электрон. 2010. Т. 40. № 2. С. 103-107.

[22] Bochkov V.D., Kazantsev S.Yu., Kononov I.G., Podlesnikh S.V. // Proc. VIII Intern. Conf. on Plasma Physics and Plasma Technology. Minsk. 2015. Vol. II. P. $459-462$.

[23] Бельков Е.П., Дамук П.Н., Спичкин Г.Л., Фомин В.М. // Письма в ЖТФ. 1986. Т. 12. Вып. 23. С. 278-281.

[24] Елеикий А.В. // УФН. 1978. Т. 125. Вып. 2. С. 279-214.

[25] Бычков Ю.И., Ямпольская С.А., Ястремский А.Г. // Квант. электрон. 2010. Т. 40. № 1. С. 28-34.

[26] De Angelis A., Lazzaro P., Garosi F., Giordano $G$., Letardi T. // Appl. Phys. B. 1988. Vol. 47. N 1. P. 1-6.

[27] Бычков Ю.И., Горчаков С.Л., Ястремский А.Г. // Квант. электрон. 2000. Т. 30. № 8. С. 733-737.

[28] Lyman J.L. // Appl. Opt. 1973. Vol. 12. N 11. P. 2736-2747.

[29] Arnold C.P., Wenzel R.G. // Quant. Electron. 1973. Vol. QE-9. N 4. P. 491-493.

[30] Ostrovskaya G.V., Zaidel A.N. // Phys. Lett. A. 1968. Vol. 26. N 9. P. 393-394.

[31] Kruger G. // Appl. Opt. 1982. V.21. ?15. P. $2841 ? 2844$.

[32] Великанов С.Д., Елугин А.С., Кудряшов Е.А., Пегоев И.Н., Синьков С.Н., Фролов Ю.И. // Квант. электрон. 1997. Т. 24. № 3. C. 279-282.

[33] Vainos N.A., Mailis S., Pissadakis S., Boutsikaris L., Dainty P., Parmiter P.J.M., Hall T.J. // Appl. Opt. 1996. V. 35. N 32. P. 6304-6319. 